\title{
correspondence
}

\section{Separating swimmers}

SIR,-Within the past few years the electronic timer, capable of responding to time differences of $.001 \mathrm{~s}$, has replaced the stop-watch, capable of responding to time differences of perhaps $.05 \mathrm{~s}$. In world class swimming events are now decided and records are established by amounts down to $.01 \mathrm{~s}$. Detailed regulations for the use of such devices are given in the handbook of the international swimming federation FINA. A recent modification to these regulations, passed at the Montreal Olympic Congress in 1976, prohibits the separation, even for placing, of swimmers by times less than $.01 \mathrm{~s}$. Clearly, the significance of such accurate timing needs examination.

According to FINA Regulation, a pool for an Olympic or for a World Games must have a length of $50.00 \mathrm{~m}$ with a "tolerance of $+.03 \mathrm{~m}$ ". In other words, the maximum permissible error in length, from one pool to another, is $+0.06 \%$. This error is recurrent and will remain the same, no matter how many lengths of the pool are swum. If timing is conducted to one-hundredth of a second electronically, that is to $\pm .01 \mathrm{~s}$, the maximum possible timing error in the fastest event, the Men's $100 \mathrm{~m}$ Freestyle swum in a typical time of $50 \mathrm{~s}$, is $0.02 \%$. The timing error of $0.01 \mathrm{~s}$ is not recurrent, and so the percentage timing error decreases for longer distance races, taking longer times.

It is well known that the overall accuracy of any measurement is set by the least accurate measurement. For the example above, the Men's $100 \mathrm{~m}$ Freestyle, the maximum possible error, $0.06 \%$, is three times the maximum possible timing error of $0.02 \%$, the ratio becoming more unfavourable for longer distances.

It is therefore not valid to compare records made in different pools, unless the times can be corrected to the exact length of the pool, or unless the time difference is, in the case of the Men's $100 \mathrm{~m}$ Freestyle, at least $0.03 \mathrm{~s}$ and correspondingly greater for longer distances up to a maximum of about $0.5 \mathrm{~s}$ for the Men's $1,500 \mathrm{~m}$ swum in a typical time of about 15 minutes. Current listings of world records do not appear to make this distinction, and there is no indication that the records have been corrected to the appropriate pool length. Although in practice many records are established by better margins, in some cases, especially over shorter distances, $0.01 \mathrm{~s}$ separation has been the deciding factor.

The figures quoted are typical and not, of course, exact. This does not alter the argument or the general conclusion, however. As surveyor's measurements are usually more accurate than the FINA tolerance of $+0.06 \%$, it might be better to specify all records after correction to the 'exact' (that is, the surveyor's) pool length, rather than to attempt to define separation times for each event and every pair of pools. The correction could be programmed into the electronic timer itself. In fact, it is the velocity of the swimmer that is really of interest. Time is used as a convenient indicator, but the assumption is implicit that all course lengths are all known exactly to be equal. Similar arguments may apply in other sports.

Other points might also be mentioned:

- If all the lanes in a given pool are known to be of equal length it may be valid to separate swimmers to $0.01 \mathrm{~s}$ accuracy.

- The well-known problem of the velocity of the sound of the starter's gun is accounted for by separate horns, one at each starting block, each linked to the timer and to the starter's gun. If this is not done, the swimmer in the farthest lane from the gun will start with a disadvantage of some 0.03 to $0.06 \mathrm{~s}$, depending on the pool width and the position of the starter along the side of the pool.

- Expansion of the pool with changing water temperature has sometimes been cited as another possible source of error. Water temperature must be maintained at a minimum of $77^{\circ} \mathrm{F}$ and is unlikely to exceed this by more than a few degrees. For typical materials and temperature ranges the effect of expansion is about an order of magnitude smaller than the pool length tolerance and is not, therefore, significant.

$$
\text { Yours faithfully, }
$$$$
\text { C. H. BARROW }
$$

University of the West Indies,

Kingston, Jamaica

\section{Carcinogens and cancerogens}

SIR, - The amusing exchange between Lijinsky and Jukes (7 April, page 494) appeared even more droll because they both used the term carcinogen in such a way as to leave question to their meaning. 'Carcinogen' should refer to the production of carcinomas, that is, tumors of epithelium. Agents that produce sarcomas, leukemias or other neoplasia as well as carcinomas should properly be called cancerogens. I doubt that either correspondent intended to limit their meaning to substances producing only carcinomas-they have followed a widespread but incorrect usage.

$$
\text { Yours faithfully, }
$$
Cecil H. Fox

Solna, Sweden

\section{Inexhaustible energy}

SIR,-J. Tuzo Wilson (20 January, page 196) has argued that economics must change because the era of cheap energy is past. Many scientists have claimed that the watchword of the next era will be inexhaustible energy. $R$. W. Cahn (10 March, page 106) has given reasons why fusion power does not really meet this description.

A current campaign, in the United States at least, is to build solar energy collectors in space, and beam energy to the Earth's surface. It is said these would last as long as the Sun does. I feel there must be some flaw in this "inexhaustible energy source" too, and wish someone would tell me what it is Yours faithfully, D. W. Allan

Toronto, Canada

\section{Power station in the sea}

SiR,-In a short note (31 March, page 402) you say that Loviisa-the location of Finland's first nuclear power station-is south of Helsinki. Have you looked at the map to see where, if this were true, it would be?

Yours faithfully,

Otaniemi, Finland

$$
\text { STIG-OlOF LONDEN }
$$

\section{Molecular biology lab}

SIR-There is no truth in your report (28 April, page 768) that the Governing Board of this Laboratory will be disbanded when Perutz retires in September 1979.

$$
\begin{aligned}
& \text { Yours faithfully, } \\
& \text { M. F. PERUTZ } \\
& \text { SYDNEX BRENNER }
\end{aligned}
$$

MRC Laboratory of Molecular

Biology,

Cambridge, UK 